\title{
Kant e o ceticismo: complemento histórico a um artigo de Z. Loparic
}

\section{Kant and skepticism: historical complement to a Z. Loparic's paper}

\author{
Joãosinho Beckenkamp ${ }^{1}$ \\ Universidade Federal de Minas Gerais \\ E-mail: jobeqk@gmail.com
}

Resumo: a relação da filosofia kantiana com o ceticismo é objeto de investigação praticamente desde a primeira recepção da filosofia transcendental, atingindo um primeiro clímax já no início dos anos 1790. Este trabalho em homenagem ao professor Zeljko Loparic retoma um artigo seu sobre o tema, e mostra o acerto das teses por ele propostas à luz de pesquisa mais recente e detalhada.

Palavras-chave: Kant; Crítica; Ceticismo.

\begin{abstract}
Kant's philosophy to skepticism has been the subject of investigation practically since the first reception of transcendental philosophy, reaching a first climax as soon as the early 1790s. This paper in honor of Professor Zeljko Loparic takes up an article of his on the subject, and shows the correctness of the theses proposed by him in the light of more recent and detailed research.
\end{abstract}

Keywords: Kant; Criticism; Skepticism.

Em um número da revista "Manuscrito" dedicado ao ceticismo, Loparic publicou, em 1988, um artigo com o título "Kant e o ceticismo", no qual se encontram delineados os aspectos essenciais da relação de filósofo com o ceticismo. Tendo em vista ressaltar a importância dessa contribuição para os estudos kantianos no Brasil, apresentarei as teses centrais do artigo, complementando seu resultado com uma contextualização histórica que pode ser útil para quem se interessa pela história do desenvolvimento do pensamento filosófico.

O primeiro passo do artigo de Loparic consiste em corrigir uma injustiça histórica que se encontra perpetrada em uma bastante difundida tese de que Kant teria pretendido refutar o ceticismo, particularmente o de Hume:

\footnotetext{
${ }^{1}$ Professor Titular da UFMG. Como pesquisador da filosofia alemã clássica, publicou os livros Entre Kant e Hegel (EDIPUCRS, 2004), O jovem Hegel, Formação de um sistema pós-kantiano (Loyola, 2009), Introdução à filosofia crítica de Kant (Editora UFMG, 2017) e Ceticismo e idealismo alemão (Loyola, 2019). Como tradutor, contribuiu com a tradução de Os sonhos de um visionário, em Kant, Escritos pré-críticos (Editora UNESP, 2005), e organizou, com introdução e tradução, Kant, Princípios metafísicos da doutrina do direito (WMF Martins Fontes, 2014).
} 
Freqüentemente se pensa que Kant tentou erradicar o ceticismo da filosofia, recolocando a metafísica sobre fundamentos novos e inabaláveis. Esse teria sido o triunfo sobre Hume por ele almejado. Na realidade, as coisas são bem diferentes. Kant não tentou expurgar o ceticismo, mas, pelo contrário, levá-lo às últimas conseqüências para poder, depois dessa radicalização, domesticá-lo definitivamente (Loparic, 1988, p. 67).

Sem dúvida, foram desenvolvidas muitas leituras dogmáticas de Kant, visando essencialmente demonstrar a continuidade da filosofia transcendental kantiana com a milenar tradição do pensamento metafísico ocidental. Para essas leituras, a relação de Kant com o ceticismo só pode ter sido a do refutador, cabendo à Filosofia sustentar as pretensões de conhecimento metafísico contra os ataques céticos. Curiosamente, desenvolve-se, no período da primeira recepção da filosofia kantiana, uma linha de objeção supostamente cética à filosofia transcendental, que se nutre fundamentalmente da atribuição a Kant de uma intenção de refutar o ceticismo, coroando seu esforço especulativo com uma refundação da metafísica em novas bases. Mais justo com o projeto kantiano é o posicionamento de Loparic, que entende inclusive o núcleo duro da filosofia transcendental como transformação dos conceitos da ontologia em categorias sustentadas no âmbito de uma analítica do entendimento, a qual Loparic, em seu projeto global de interpretação de Kant, chama de semântica transcendental.

O que vale para a ontologia, vale também para a metafísica em geral: "A crítica kantiana da razão teórica é, portanto, tudo menos um novo fundacionalismo filosófico que visasse salvar a metafísica tradicional. Enquanto conhecimento do suprassensível, esta última fica definitivamente descartada" (Loparic, 1988, p. 69).

Como mostrei em outro lugar (Beckenkamp, 2019), a relação apontada por Loparic entre filosofia, metafísica e ceticismo caracteriza não só Kant, mas os projetos mais relevantes do idealismo alemão. Fichte, por exemplo, em nota avulsa datada de 1795, adverte que a passagem pela dúvida cética é uma precondição para entender o que ele se propõe com filosofia: "Quem ainda não entendeu Hume [e outros], não tendo ainda chegado a um acordo com eles sobre os pontos por eles propostos, tampouco está maduro para a doutrina da ciência: ela lhe responde questões que ele ainda não se pôs" (Fichte, 1971, p. 389). E ainda Hegel, tantas vezes lido como um restaurador do dogmatismo metafísico, caracteriza sua Fenomenologia do espírito como "ceticismo que se realiza a si mesmo" (Hegel, 1980, p. 56). Em vez de contestar a esses autores suas asseverações em favor do ceticismo, será mais produtivo levá-las a sério e empreender um esforço de interpretar seu pensamento como estando em permanente confronto com quaisquer objeções céticas.

No caso de Kant, esse confronto é mantido em relação a Hume no que tange a parte fundamental de sua filosofia transcendental, a saber, a analítica transcendental. Como Loparic constata em seu artigo, Kant se viu desafiado pelo ceticismo humeano e não por ensaios anteriores, como a assim chamada dúvida hiperbólica de Descartes: 
Na sua tentativa de radicalizar o ceticismo, Kant parte de Hume e não de Descartes. Apesar do extremismo da dúvida hiperbólica, este último rendeu-se depressa demais às aparentes evidências da razão e não conseguiu pôr em questão o valor objetivo do princípio de causalidade. É nele que repousa toda sua metafísica, bem como a de Locke e Leibniz. O ataque humeano ao princípio de causalidade pôs fim a esse tipo de teorização na filosofia. A faísca que ele produziu acendeu a luz na qual Kant foi capaz de avistar a esfera finita da certeza filosófica. Mas, para tanto, foi preciso ser mais radical que Hume (Loparic, 1988, p. 70).

Se nos fiarmos nas afirmações de Kant, este parece ter tido um conhecimento muito limitado do ataque humeano à velha metafísica, que vai muito além de um ataque ao princípio de causalidade, também atingindo diretamente as noções metafísicas de substância, objeto, identidade pessoal etc. Mas o ataque de Hume à objetividade do princípio de causalidade é, por si só, suficiente para colocar em xeque as construções metafísicas dos cartesianos, na medida em que corta o liame lógico entre a representação mental e sua suposta causa em uma relação objetiva ou na coisa. Falando a linguagem de Kant, sem o princípio de causalidade como garantia do nexo ontológico entre representação e coisa, deixam de ter qualquer fundamento as pretensões de conhecimento da coisa em si, seja na metafísica, como pretenso conhecimento da natureza última das coisas, seja na ciência da natureza, como pretenso conhecimento da verdade definitiva dos fenômenos e suas leis físicas.

$\mathrm{O}$ conhecimento que Kant tinha do ataque de Hume à metafísica parece ter sido bastante vago. Assim, na primeira edição da "Crítica da razão pura", Kant não menciona Hume no contexto em que se ocupa da causalidade e dos demais conceitos puros do entendimento, fazendo-o tão somente em uma parte da doutrina do método em que se trata de apontar para a insuficiência do ceticismo na satisfação da razão pura consigo mesma. No caminho que leva do dogmatismo ao criticismo, passando pelo ceticismo (cf. KrV, A 761/B 789), Hume é reconhecido como o mais espirituoso de todos os céticos e "sem dúvida o melhor em vista da influência que o procedimento cético pode ter para o despertar de um profundo exame da razão" ( $\mathrm{KrV}$, A 764/B 792). Aqui, e não na analítica transcendental, Kant conjectura que Hume talvez tivesse entendido "que nós, em juízos de certa espécie, vamos além de nossos conceitos do objeto" (KrV, A 764/B 792).

Pois Hume havia, na "Investigação sobre o entendimento humano", colocado em questão as proposições de causalidade, mostrando a impossibilidade de enquadrá-las na divisão básica entre relações de ideias e matérias de fato (que corresponde, grosso modo, à distinção kantiana entre juízos analíticos e sintéticos a posteriori). Afirmando mais do que se pode estabelecer com base em simples relações de ideias, proposições causais tampouco podem ser derivadas simplesmente do que se observa nos objetos. A solução que Hume fornece é a da inteira subjetivação, reduzindo tais proposições a uma simples expressão de expectativas geradas pelo hábito que se estabelece sob a atuação da imaginação frente à repetição de casos semelhantes. A solução que Kant ensaia é de 
natureza bem diferente, mas o problema teria sido levantado com suficiente clareza por Hume, ainda que só em relação ao princípio da causalidade (cf. KrV, A 760/B 788).

A relação do programa da filosofia transcendental com o problema levantado por Hume tinha sido expressa, portanto, na edição de 1781, mas sem particular ênfase e, ainda por cima, longe do lugar em que é apresentada a sua solução. O posterior estreitamento de laços com Hume pode ser entendido como resposta de Kant ao tratamento negativo que a "Crítica da razão pura" recebeu em uma resenha publicada em 1782 na revista de resenhas "Göttingische Gelehrte Anzeigen". Essa resenha, feita por Garve, mas fortemente emendada por Feder, o editor da revista, muito irritou Kant. Não sabendo bem o que fazer com o novo lance do filósofo de Königsberg, Garve e Feder sugerem relações da obra tanto com o idealismo de Berkeley, por propor que o entendimento faz os objetos a partir das aparências sensíveis, quanto com o ceticismo de Hume, o que em um contexto marcado pelos ataques dos defensores do senso comum às consequências das filosofias tanto de Berkeley quanto de Hume significa um ataque também à filosofia proposta na "Crítica da razão pura".

A resposta de Kant veio em 1783, nos "Prolegômenos a toda metafísica futura" e pode ser desmembrada em duas partes, uma voltada contra a acusação de idealismo e outra estreitando a relação com Hume. Em apêndice no fim dos "Prolegômenos", Kant dedica mais de dez páginas a uma resposta multifacetada à resenha da revista de Göttingen, explicitamente mencionada na abertura. Queixa-se da incompreensão de sua proposta, desafia o resenhista a descer das generalidades e apresentar sua posição em um tópico particular, "como, p. ex., a permanência da substância ou a necessária determinação dos acontecimentos no mundo através de sua causa" (Prol, AA 04: 378), mas reage, sobretudo, à leitura que coloca seu programa do idealismo transcendental ao lado do idealismo de Berkeley, para o qual "todo conhecimento pelos sentidos e pela experiência nada é senão pura ilusão" (Prol, AA 04: 374). A filosofia transcendental proposta por Kant, ao contrário, toma o conhecimento pela experiência como único conhecimento objetivo de que dispomos, submetendo à crítica qualquer pretensão de conhecimento além da experiência. $\mathrm{O}$ afastamento em relação àquele tipo de idealismo marca já uma série de passagens dos "Prolegômenos", mas será concluído na refutação do idealismo empreendido na segunda edição da "Crítica da razão pura".

Já em relação às insinuações feitas na resenha de que a obra não se destacaria suficientemente do ceticismo e de Hume, a resposta de Kant vai no sentido oposto, reforçando a relação e assumindo publicamente a influência sofrida por esse lado: "Eu admito francamente que foi justamente a lembrança de David Hume que, há muitos anos, interrompeu por primeiro meu sono dogmático, conferindo a minhas investigações no campo da filosofia especulativa uma direção bem diferente" (Prol, AA 04: 260). E com endereço certo, visto que a revista de Göttingen era porta-voz de ideias vindas da Grã-Bretanha, Kant desfere um golpe decisivo contra os detratores de Hume, identificandose com o destino da incompreensão de seu propósito: 
Mas o destino, desde sempre desfavorável à metafísica, quis que ele não fosse entendido por ninguém. Não se pode assistir sem sentir uma certa pena como seus adversários Reid, Oswald, Beattie e, por fim, também Priestley erraram completamente o ponto de seu problema, tomando sempre por admitido aquilo que ele justamente duvidava e, por outro lado, demonstrando com veemência e em geral com grande imodéstia aquilo que nunca lhe ocorreu duvidar, com o que ignoraram de tal maneira sua indicação de melhoria, que tudo ficou no velho estado, como se nada tivesse acontecido (Prol, AA 04: 258).

O contra-ataque lançado, assim, por Kant marcou o declínio da filosofia do senso comum na Alemanha, ao mesmo tempo que levou a uma recepção acalorada do ceticismo humeano na década seguinte.

Na segunda edição da "Crítica da razão pura", de 1787, Kant finalmente menciona Hume, ao lado de Locke, no lugar devido, ou seja, na preparação para sua dedução transcendental das categorias, entre as quais se encontra justamente a da causalidade. Além disso, explicita sua relação com o problema levantado por Hume acerca do princípio da causalidade em acréscimo à introdução da obra, reafirmando que Hume foi aquele que mais se aproximou da tarefa central de toda Filosofia, qual seja, a de mostrar como são possíveis juízos sintéticos a priori. Não decerto por uma eventual resposta, mas por ter colocado claramente o problema, pelo menos no que diz respeito ao princípio de causalidade; problema que Kant pretende estender a toda a metafísica (cf. KrV, B 19).

Aceitando, assim, o desafio lançado pelo ataque de Hume à metafísica, Kant elabora uma teoria do conhecimento que leva em conta os limites que são colocados à experiência humana. Como observa Loparic, "é a Kant que se deve o mérito de ter elaborado uma primeira teoria crítica dos limites necessários do conhecimento, iniciando assim uma linha de investigação que visa internalizar o ceticismo na teoria do conhecimento e dessa forma domesticá-lo definitivamente" (Loparic, 1988, p. $74)$.

Com isto está elucidado essencialmente o que o ceticismo humeano significou para Kant. Uma investigação histórica pode ajudar a esclarecer uma duplicidade na indicação da origem do despertar de Kant para o caminho do criticismo, que Loparic registra em seu artigo sem lhe dar maior importância:

Segundo os Prolegomena, Kant despertou do sonho [sic] dogmático e veio a conceber a ideia da crítica da razão enquanto teoria da demonstrabilidade das proposições filosóficas, partindo da demolição humeana da prova de uma proposição particular, a saber, do princípio de causalidade. Segundo um outro texto, a origem dessa nova ciência teria sido diferente (Loparic, 1988, p. 76-7). 
Este outro texto é uma famosa carta a Garve, de 21 de setembro de 1798, na qual Kant relembra essa descoberta decisiva nos seguintes termos:

Não foi a investigação da existência de Deus, da imortalidade etc. o ponto de que parti, mas foi a antinomia da razão pura - "O mundo tem um começo, ele não tem um começo etc., até a quarta: existe liberdade no homem, contra: não existe liberdade, mas tudo nele é necessidade natural" - que me despertou inicialmente do sono dogmático e me impeliu para a crítica da própria razão para superar o escândalo da aparente contradição da razão consigo mesma (Br, AA 12: 257-8).

Essa lembrança tardia tem sua confirmação, aliás, em uma passagem dos "Prolegômenos"

Este produto da razão pura em seu uso transcendental [as ideias cosmológicas] é o mais notável fenômeno da mesma, o qual também atua mais do que qualquer outro e da maneira mais vigorosa no sentido de despertar a filosofia de seu sono dogmático e de levá-la ao difícil negócio da crítica da própria razão (Prol, AA 04: 338).

Ora, aqui se anuncia mais do que uma simples versão alternativa do despertar do sono dogmático. Se na primeira versão o pontapé inicial é atribuído a Hume, expressando-se nela o profundo reconhecimento da dívida em relação ao ataque humeano à metafísica, nessa segunda versão se articula uma influência que Kant não chega a tornar explícita, mas que podemos reconstruir a partir do contexto histórico; a saber, a influência do ceticismo antigo. Se na analítica transcendental foi decisiva a influência do ceticismo humeano, como Kant foi progressivamente reconhecendo, na dialética transcendental e na compreensão do método da razão pura se faz presente antes o ceticismo antigo, um aspecto da relação de Kant com o ceticismo que é menos estudado. No desenvolvimento do idealismo pós-kantiano, entretanto, esse aspecto terá um desdobramento de suma importância.

Na literatura kantiana, tem sido discutido se Kant chegou a ler "Sexto Empírico", a principal fonte tanto no que diz respeito à terminologia quanto às teses centrais associadas ao ceticismo antigo. O mais provável é que esse não tenha sido o caso, tendo o contato de Kant com o ceticismo antigo ocorrido através de fontes secundárias. Apesar do filósofo empregar vez ou outra expressões provindas do ceticismo antigo já nos anos 1750, é por volta de 1770 que se faz notar uma influência significativa, portanto em um momento crucial do desenvolvimento do pensamento kantiano. Nessa altura, Kant começa a praticar o que virá a chamar de antitética, termo com que "Sexto Empírico" justamente caracteriza o método cético. A acima mencionada carta a Garve não indica uma data em que o procedimento de oposição de tese e antítese teria começado a causar seus efeitos céticos ou críticos no pensamento de Kant; mas, em uma reflexão de meados dos anos 1770, Kant menciona o ano de 1769 como crucial nesse sentido: "Inicialmente, vi este sistema como num crepúsculo. Eu tentava muito 
seriamente demonstrar proposições e seu oposto, não para erigir uma doutrina cética, mas, porque eu suspeitava de uma ilusão do entendimento, para descobrir no que ela consistia. O ano de 69 me trouxe grande luz" (Refl 5037, AA 18: 69).

Que Kant se ocupou bastante, aliás, do ceticismo em torno de 1770, prova-o o largo tratamento a ele conferido nas lições sobre lógica datadas de $1771,^{2}$ das quais um certo Blomberg conseguira uma cópia (daí o seu nome: "Lógica Blomberg"). Nessas lições, se trata, sobretudo, do ceticismo antigo, do seu método de contrapor tese e antítese e de sua importância para a Filosofia. Em boa medida, Kant expõe àquela altura como mérito dos céticos aquilo que depois constituirá o lado negativo de sua crítica da razão pura:

Mas, bem considerado, os céticos certamente foram bem mais úteis à filosofia do que os orgulhosos dogmáticos [...] O ceticismo ou o método da dúvida cética, quando se desconfia de si mesmo, pondera os fundamentos a favor e contra o conhecimento que se tem e se esforça para chegar deste modo à completa certeza dos mesmos, este ceticismo é o melhor catártico, o melhor purgante da razão. (V-Lo/Blomberg, AA 24: 208).

A antitética como meio catártico de que o cético se vale para purgar seu juízo é uma analogia que se encontra repetidas vezes em "Sexto Empírico", tendo nele sua origem mais provável. Como é bem conhecido dos leitores de Kant, essa apreciação do ceticismo como catártico da razão é estendida à própria crítica na "Crítica da razão pura":

Esta é a grande utilidade que tem a maneira cética de tratar as questões que a razão pura faz à razão pura, e pela qual se pode ser dispensado de uma grande confusão dogmática sem muito esforço, colocando em seu lugar uma crítica sensata que, como um verdadeiro catártico, eliminará oportunamente a ilusão junto com sua acompanhante, a presunção (KrV, A 486/B 514).

Como dito, antitética é um termo que se encontra em "Sexto Empírico" para caracterizar o

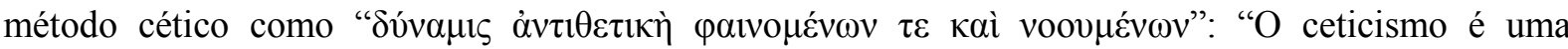

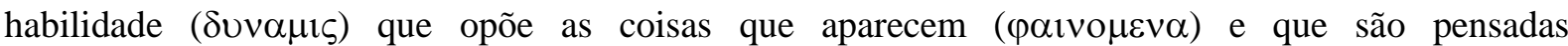
(voou $\mu \varepsilon v \omega v)$ de todos os modos possíveis" (Sexto Empírico, 1997, p. 116). Ora, na tradução tanto para o latim quanto para o francês (que Kant poderia ter lido, visto que não havia então tradução

\footnotetext{
${ }^{2}$ Os critérios para essa datação se encontram na introdução do editor Gerhard Lehmann (cf. V-Lo, AA 24: $977-$ $8)$.
} 


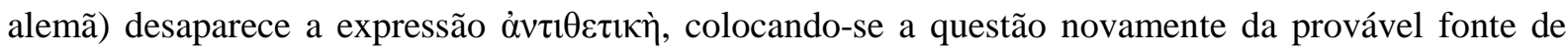
Kant para a sua adoção. Como em tantos outros termos adotados por Kant, é em Baumgarten que se encontra o emprego (latinizado) da expressão. Ele o faz já na "Acroasis logica" de 1761, ao dar a um dos capítulos o título: "De refutando, polemica, antithetica". Nesse capítulo, Baumgarten trata da técnica da refutação de uma tese, contrapondo-lhe uma antítese, de onde a expressão "antitética" para caracterizar esta arte da polêmica: "A tese posta pelo impugnado e suprimida pelo impugnante é controversa, e a que lhe é oposta para que se negue que ambas sejam verdadeiras é a antítese" (Baumgarten, 1761, p. 195). Para Baumgarten, portanto, a antitética é a técnica da refutação e da polêmica, estando associada à antítese oposta a uma tese; a definição da antitética na "Crítica da razão pura" se opõe a esta concepção, estando mais de acordo com a antitética pirrônica apresentada por Sexto Empírico.

Para a associação mais direta do termo antitética com Sexto Empírico, entretanto, é preciso recorrer à publicação póstuma, no ano de 1770, da "Philosophia generalis" de Baumgarten, na qual este contrapõe tética (que trata da certeza subjetiva ou convicção e de seus graus até a incerteza subjetiva, do parágrafo 47 ao 86) e antitética (que trata do hábito cético de nem afirmar nem negar, também chamado zetético, eclético e aporético, do parágrafo 87 ao 140). Sob o título de antitética, Baumgarten trata, pois, do ceticismo, recapitulando inclusive os passos decisivos de sua história, desde os pré-socráticos até Bayle; ele só não cita ninguém, como é usual entre os wolffianos. A remissão direta a Sexto Empírico se encontra, entretanto, no longo proêmio do editor do texto, Johann Christian Foerster, o qual empreende uma verdadeira apologia da dúvida como momento preparatório

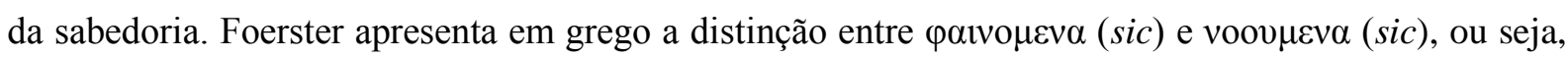
entre as coisas que são percebidas pelos sentidos e as que só podem ser pensadas pela mente. No mesmo parágrafo, traça considerações sobre a função dessa distinção no pirronismo e na academia. Em vista da coincidência de datas, tem-se aqui uma provável fonte para a distinção entre sensível e inteligível na "Dissertação" de 1770, na qual Kant menciona que os antigos tinham desenvolvido essa distinção, distribuindo-a em fenômenos e númenos: "O objeto da sensibilidade é sensível, mas o que nada contém a não ser o que pode ser conhecido por inteligência é inteligível. O primeiro se chamava nas escolas dos antigos de Phaenomenon, o último de Noumenon" (MSI, AA 02: 392)³.

Para a concepção de antitética que Kant apresentará mais tarde, é bastante significativo o fato de Foerster citar no original grego a definição de ceticismo dada por Sexto Empírico em HP I, 8. Kant

\footnotetext{
${ }^{3}$ Que a fonte seja Foerster ou algum manual, e não Sexto Empírico, torna-se provável se se considera que, na sequência, Sexto Empírico apresenta justamente a distinção entre sensível e inteligível, que marca a "Dissertação" de 1770: "As coisas que aparecem (

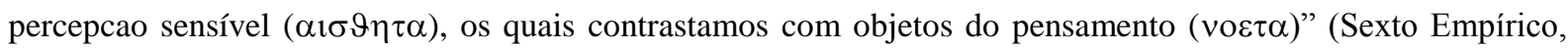
1997, p. 116). Kant lembra só em 1781 que "entre os antigos a divisão do conhecimento em

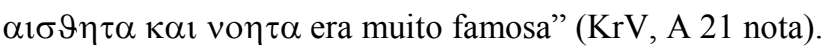


certamente conhecia suficiente grego para identificar nessa definição uma noção de antitética mais abrangente do que a sugerida por Baumgarten. Ao mesmo tempo, entretanto, Foerster propõe uma interpretação restritiva da antitética pirrônica, dizendo que os pirrônicos ou céticos contrapunham os númenos aos fenômenos e, ainda, os fenômenos aos fenômenos, excluindo assim a terceira alternativa (que será decisiva no desenvolvimento da dialética kantiana a partir do reconhecimento de uma antitética inevitável da própria razão pura, que assim se revela antagônica em si mesma), a saber, a contraposição de númenos a númenos. De acordo com essa interpretação restritiva, então, Foerster

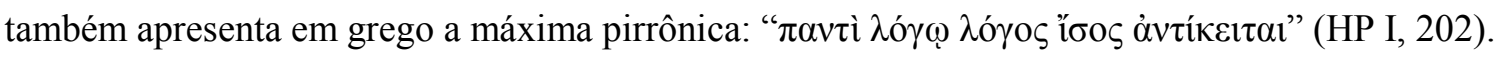

Para o desenvolvimento da própria concepção de uma crítica da razão pura, foi decisiva a identificação de uma antitética inevitável da razão; ora, a antitética como método do pensamento caracteriza justamente, como visto acima, o ceticismo antigo ou o pirronismo, tal qual apresentado por Sexto Empírico. Na parte negativa da crítica da razão pura, em que a descoberta da antitética da razão pura revela uma incontornável dialética desta razão desconectada da experiência, ou seja, uma verdadeira lógica da ilusão, encontra-se, portanto, uma marcante influência, não do ceticismo moderno, mas do ceticismo antigo.

Inicialmente, Kant parece querer circunscrever essa antitética ao campo da cosmologia, ou seja, ao pensamento da unidade incondicionada dos fenômenos:

quando aplicamos a razão à síntese objetiva dos fenômenos, [...] mostra-se um novo fenômeno da razão humana, a saber, uma antitética inteiramente natural, que ninguém precisa arquitetar e armar artificialmente, mas a que a razão chega por si mesma e de fato inevitavelmente, sendo com isto certamente resguardada do sono de uma convicção presunçosa que é produzida por uma aparência meramente unilateral, mas ao mesmo tempo tentada ou a se entregar a uma desesperança cética ou a adotar uma teimosia e pôr a cabeça dura em certas afirmações, sem prestar ouvido e justiça aos fundamentos do contrário (KrV, A 407/B 433-4).

A antitética a que a razão chega na tentativa de uma síntese absoluta dos fenômenos tem, pois, o efeito salutar de a despertar de sua presunção dogmática. Cabe agora à crítica da razão pura evitar tanto o ceticismo total quanto o refúgio nas pretensões infundadas do senso comum, como haviam feito há pouco os detratores de Hume.

$\mathrm{Na}$ apresentação da antitética da razão pura, Kant se vale da distinção feita por Baumgarten, na "Philosophia generalis" de 1770, entre tética e antitética: 
Se tética é qualquer conteúdo de doutrinas dogmáticas, entendo por antitética, não a afirmação dogmática do contrário, mas o conflito dos conhecimentos aparentemente dogmáticos (thesin cum antithesi), sem aprovar mais a exigência de aprovação de um do que do outro. A antitética não se ocupa, portanto, de afirmações unilaterais, mas considera conhecimentos universais da razão, só que de acordo com o conflito dos mesmos entre si (KrV, A 420-1/B 448).

Em relação às ideias e princípios da cosmologia racional, estabelece-se uma antitética transcendental como "uma investigação sobre as antinomias da razão pura, as causas e o resultado das mesmas" (KrV, A 421/B 448). A antitética é especificada aqui como antinomia porque não se trata da contraposição de proposições quaisquer, mas de leis ou princípios, uma da razão pura em si mesma (tese) e outra do entendimento (antítese).

A especificação da antitética como antinomia não altera em nada o fato de que se trata de uma herança cética; pelo contrário, o próprio capítulo da antinomia da razão pura se revela, assim, como uma extensão ou aplicação do método antitético provindo do ceticismo antigo. O que significa que Kant se vale na parte mais central de sua crítica da razão pura de um método que já havia sido desenvolvido e empregado pelos antigos; e ele o caracteriza mesmo como método cético: "Este procedimento de assistir ao conflito das asserções, ou até de provocá-lo por si mesmo, não para decidir em favor de uma ou da outra parte, mas para investigar se o objeto da mesma não é porventura uma simples ilusão, [...] este procedimento, digo, pode ser chamado de método cético" (KrV, A 423-4/B 451). O que não significa, entretanto, deixar o campo ao ceticismo nas questões fundamentais da razão pura: "Ele [método cético] é totalmente distinto do ceticismo, um princípio de uma ignorância artificial e científica que mina os fundamentos de todo conhecimento para, se possível, não deixar em parte alguma confiabilidade e segurança do mesmo" (KrV, A 424/B 451).

O emprego do método cético como procedimento decisivo na crítica da razão pura não visa abalar a confiança na razão, deixando tudo na incerteza, mas visa a própria certeza, ainda que não seja fácil atingi-la:

Pois o método cético visa certeza ao procurar descobrir o ponto do mal-entendido em tal conflito, levado de ambas as partes com honestidade e entendimento, para, como fazem legisladores sábios, do embaraço dos juízos em litígio tirar para si mesmos uma lição sobre a imperfeição e a indefinição em suas leis. A antinomia que se revela na aplicação das leis é, em nossa limitada sabedoria, o melhor teste da nomotética, para assim chamar a atenção da razão, que em especulação abstrata não percebe facilmente seus erros, para os momentos na determinação de seus princípios ( $\mathrm{KrV}$, A 424/B 4512). 
$\mathrm{Na}$ dialética transcendental, entretanto, Kant limita a antitética à esfera da cosmologia, identificando-a nas antinomias da razão pura. Nessas antinomias, se trataria, aliás, de uma "antitética aparente" (KrV, A 740/B 768), porque tese e antítese se referem a momentos distintos das operações cognitivas, respectivamente razão pura e entendimento. Que se poderia descobrir a antitética da razão pura também na psicologia e na teologia só é dito na doutrina do método. Como nessas duas esferas a razão pura se ocupa tão somente de si mesma, quer dizer, das ideias que ela mesma gera, sem haver um correspondente campo de fenômenos a ser levado em consideração, Kant é levado a admitir inicialmente que nelas não se trata apenas de uma antitética aparente:

Mas não se pode alegar tal mal-entendido e encerrar assim a disputa da razão se, por exemplo, fosse afirmado teisticamente que existe um ser supremo e ateisticamente, ao contrário, que não existe um ser supremo; ou na psicologia: tudo o que pensa é de uma unidade permanente absoluta e, portanto, distinta de toda unidade material transitória, ao que um outro contrapusesse: a alma não é unidade imaterial e não pode ser excetuada da transitoriedade (KrV, A 741/B 769).

Nesse caso, a antitética é insuperável em teoria, mas também aqui não há o que temer por faltar qualquer base sólida tanto para sustentar a tese quanto para suportar a antítese: "Deste modo, não há propriamente uma antitética da razão pura. Pois o único campo de batalha para a mesma teria de ser encontrado no campo da teologia e psicologia puras, mas este chão não suporta nenhum combatente com armadura completa e com armas que tivessem de ser temidas" (KrV, A 743/B 771). Além da vacuidade nesse conflito antitético da razão pura consigo mesma, é decisivo o interesse da razão prática pura, que se decide por um dos lados (pela tese, na qual vê atendidas as exigências da moral); o que lhe é facultado fazer, pois "é apoditicamente certo que nunca há de aparecer qualquer homem que possa manter o contrário com a mínima aparência de verdade, muito menos dogmaticamente" (KrV, A 742/B 770).

A aparente antitética da razão pura é, pois, decisiva para a descoberta do problema da fundamentação na razão pura, mas não a deve levar à total paralisação, como teria acontecido no ceticismo. O procedimento cético da antitética cumpre, assim, uma função preparatória no conjunto da crítica da razão pura: "O procedimento cético não é, pois, em si mesmo satisfatório para as questões da razão, mas certamente propedêutico, para despertar sua cautela e apontar para meios sólidos que lhe podem assegurar suas posses legítimas" (KrV, A 769/B 797). A identificação dessa antitética da própria razão coloca em xeque o dogmatismo e suas pretensões cognitivas. No ceticismo propriamente dito, isso servia para promover a suspensão do juízo, da qual se seguiria a paz de espírito. Para Kant, essa saída é insatisfatória, pois não leva a resolver efetivamente o conflito interno da razão pura: "É 
algo aflitivo e deprimente que haja em geral uma antitética da razão pura e que esta, que representa o tribunal supremo de todos os conflitos, deva acabar em conflito consigo mesma" (KrV, A 740/B 768).

A solução apresentada pela filosofia crítica para o conflito da razão pura consigo mesma consiste em mostrar que ele só é real sob uma determinada interpretação das proposições em litígio (a interpretação do realismo transcendental, que entende que as proposições da razão pura se referem a um objeto); entendendo-se essas proposições como máximas da razão para atender a demandas diversificadas no campo do conhecimento (tese: exigência do incondicionado, colocada pela própria razão; antítese: busca da condição para um condicionado, como princípio do entendimento), é possível mostrar que elas não são efetivamente antitéticas, cumprindo cada qual uma função específica em sua respectiva esfera.

A aplicação do método cético é decisiva na filosofia crítica kantiana, pois é ela que permite estabelecer aquela equipolência de tese e antítese em questões que ultrapassam os limites da experiência, uma equipolência que se mostra necessária para manter em aberto o lugar no qual se coloca a filosofia moral, sobretudo no concernente ao conceito indispensável de liberdade. Este não poderia ser mantido se houvesse uma contradição lógica de sua admissão com o princípio de causalidade que regula todas as operações do entendimento na experiência. Ao contemplar ainda essa dimensão fundamental da filosofia kantiana, o artigo de Loparic descortina um horizonte de interpretação global da filosofia kantiana que levei a cabo em livro dedicado a filosofia crítica kantiana em seu conjunto (cf. Beckenkamp, 2017). Nada mais justo, portanto, que eu encerre esta pequena contribuição com a citação da passagem em que o artigo de Loparic articulava elementos tão importantes:

Como o princípio de causalidade natural é um dos princípios do entendimento demonstrado a priori, não poderíamos falar em conhecimento da lei da liberdade se houvesse uma contradição inevitável entre ela e a causalidade natural. Mas essa contradição não existe. Isto é uma consequiência da resposta negativa ao problema de Hume: o princípio de causalidade não se aplica ao domínio das coisas em si, ou seja, ele é indecidível no domínio a que pertence a nossa liberdade. Essa ignorância necessária deixa aberta a porta por onde pode entrar a causalidade da lei moral. Impondo-se como fato, a lei moral não encontra mais nenhuma resistência, seja prática seja teórica. // Nietzsche tinha, portanto, razão quando dizia que Kant se valia do ceticismo para salvar a moral. Kant nunca escondeu isto (Loparic, 1988, p. 79).

\section{Referências bibliográficas}


Baumgarten, A.G. (1761). Acroasis logica. Halle: Hemmerde.

Beckenkamp, J. (2017). Introdução à filosofia crítica de Kant. Belo Horizonte: Editora da UFMG.

Beckenkamp, J. (2019). Ceticismo e idealismo alemão. São Paulo: Loyola.

Fichte, J.G. (1971). Gesamtausgabe II/3. Stuttgart-Bad Cannstatt: Frommann Holsboog.

Hegel, G.W.F. (1980). Phänomenologie des Geistes. Hamburg: Felix Meiner Verlag.

Loparic, Z. (1988). Kant e o ceticismo. Manuscrito, v. 9, n. 2, pp. 67-83.

Sexto Empírico. (1997). Hipotiposes pirrônicas, livro 1 (tradução de Danilo Marcondes). o que nos faz pensar, n. 12, pp. 115-22. 